\title{
ANÁLISE DA BIOGRAFIA E DA OBRA DE FERNANDO PESSOA E OUTROS PESSOAS
}

\author{
Tania Pleszko Janusis ${ }^{1}$
}

\section{RESUMO}

Na produção literária alvo desta pesquisa, os autores objetivaram retratam os muitos "Fernandos Pessoas" para reconstruí-los como um todo, por meio da associação entre imagens e palavras, através dos recursos dos quadrinhos - HQ. Para isso, Guazzelli e Fazzolari apresentam o percurso intelectual de Fernando Pessoa como o relato de uma grande viagem de descoberta em que sempre procurou algo divino e desconhecido. Nela, Pessoa agarra-se a distintos artifícios metafísicos, para conseguiu chegar a uma conclusão definitiva de sua singela significância no mundo. Dessa forma, os autores articulam as imagens à fala de Fernando e nos mergulha no seio do poeta e em seu mundo de ideias. A metodologia recorrida trata-se de revisão bibliográfica e de cunho qualitativo exploratório. Como conclusão deste escrito, a obra possui luz própria, os versos são fielmente transcritos e extraídos de maneiras não linear, reforçados pela linguagem dos traços e pinturas, que contribuem para melhor decodificação da mensagem. A produção transporta o leitor a um passeio de descoberta, embalados pelos versos do mestre da poesia portuguesa, Álvaro de Campos, Bernardo Soares e Alberto Caeiro, se fazem presentes nesta produção adaptada para $\mathrm{HQ}$ que, é composta por associação entre palavra e imagem, construindo uma harmonia lírica e visual dos acontecimentos narrados. Na organização da obra, Guazzelli apresenta fragmentos de quatro poemas de Fernando Pessoa que, serão analisados neste escrito.

Palavras-Chave: Literatura; Fernando Pessoa; História em Quadrinhos; Palavra; Imagens.

\begin{abstract}
In the literary production targeted by this research, the authors aimed to portray the many "Fernandos Pessoas", to reconstruct them as a whole, through the association between images and words, through the resources of comics - HQ. For that, Guazzelli and Fazzolari present Fernando Pessoa's intellectual journey as an account of a great journey of discovery in which he always sought something divine and unknown. In it, Pessoa clings to different metaphysical devices, in order to reach a definitive conclusion of its simple significance in the world. In this way, the authors articulate the images to Fernando's speech and immerse us in the bosom of the poet and in his world of ideas. The methodology used is a bibliographic review and an exploratory qualitative approach. As a conclusion of this writing, the work has its own light, the verses are faithfully transcribed and extracted in non-linear ways, reinforced by the language of the lines and paintings, which contribute to a better decoding of the message. The production takes the reader on a journey of discovery, packaged by the verses of the Portuguese poetry master, Álvaro de Campos, Bernardo Soares and Alberto Caeiro, are present in this production adapted for $\mathrm{HQ}$, which is composed of an association between word and image, building a lyrical and visual harmony of the events narrated. In the organization of the work Guazzelli presents fragments of four poems by Fernando Pessoa that will be analyzed in this writing.
\end{abstract}

Keywords: Literature; Fernando Pessoa; Comics; Word; Images.

\footnotetext{
${ }^{1}$ Pedagoga e especialista em Neuropsicopedagogia, professora da rede pública de São Paulo. E-mail: Tania.13pj@gmail.com
} 


\section{RESUMEN}

En la producción literaria dirigida por esta investigación, los autores pretendían retratar a los muchos "Fernandos Pessoas", para reconstruirlos en su conjunto, a través de la asociación entre imágenes y palabras, a través de los recursos del cómic - HQ. Para ello, Guazzelli y Fazzolari presentan el viaje intelectual de Fernando Pessoa como el relato de un gran viaje de descubrimiento en el que siempre buscó algo divino y desconocido. En ella, Pessoa se aferra a diferentes dispositivos metafísicos, para llegar a una conclusión definitiva de su simple significado en el mundo. De esta manera, los autores articulan las imágenes al discurso de Fernando y nos sumergen en el poeta y en su mundo de ideas. La metodología utilizada es una revisión bibliográfica y naturaleza cualitativa exploratoria. Como conclusión de esta escritura, la obra tiene su propia luz, los versos se transcriben y extraen fielmente de maneras no lineales, reforzadas por el lenguaje de las huellas y pinturas, que contribuyen a una mejor decodificación del mensaje. La producción transporta al lector a un recorrido por el descubrimiento, repleto de versos del maestro de la poesía portuguesa, Álvaro de Campos, Bernardo Soares y Alberto Caeiro, están presentes en esta producción adaptada a $\mathrm{HQ}$, que está compuesta por una asociación entre palabra e imagen, construyendo una armonía lírica y visual de los acontecimientos narrados. En la organización de la obra Guazzelli presenta fragmentos de cuatro poemas de Fernando Pessoa que serán analizados en esta escritura.

Palabras clave: Literatura; Fernando Pessoa; Cómics; Palabra; Imágenes.

\section{INTRODUÇÃO}

Neste escrito, será apresentada a biografia de Fernando pessoa bem como a análise literária e visual gráfica de uma de suas obras, intitulada: "Fernando Pessoa e Outros Pessoas".

Para dar início a esta análise, cabe ressaltar que não se tem como objetivo expressar uma verdade única, mas sim, uma interpretação enquanto leitor que aprecia diversos gêneros literários, em especial quadrinhos e poesia, bem como o trabalho da relação entre o estudo da linguagem em suas diferentes manifestações.

O legado poético de Fernando Pessoa transpassa a tipologia narrativa do pensamento metafísico e político. A obra apresenta um escritor extremante crítico, dramático, polido, literário, é sobretudo, um poeta de múltiplas características intelectuais, o que dá a obra uma riqueza de detalhes e complexidade na interpretação de sua mensagem. Os poemas adaptados para versão $H Q$ rejuvenescem a obra original, em virtude de os autores fazerem uma seleção de versos e estrofes extraídas integralmente dos poemas originais, para adequá-las a um cenário descontraído pelas cores e combinações de falas singelas, caracterizado pelos versos livres.

Na produção literária alvo desta pesquisa, os autores retratam os muitos "Fernandos Pessoas" para reconstruí-los como um todo. 
Multipliquei-me, para me sentir, Para me sentir, precisei sentir tudo, Transbordei, não fiz senão extravasar-me, Despi-me, entreguei-me, E há em cada canto da minha alma um altar a um deus diferente (GUAZZELLI; FAZZOLARI, 2011).

Guazzelli e Fazzolari (2011) apresentam o percurso intelectual de Fernando Pessoa como o relato de uma grande viagem de descoberta em que sempre procurou algo divino e desconhecido. Nela, Pessoa agarra-se a distintos artifícios metafísicos, para conseguiu chegar a uma conclusão definitiva de sua singela significância no mundo. Dessa forma, os autores articulam as imagens à fala de Fernando e nos mergulha no seio do poeta, que conclui que todos os caminhos são verdadeiros, sendo que o que realmente é preciso é navegar pelo mundo das ideias.

\section{SOBRE FERNANDO PESSOA}

De acordo com Crespo (1988), nascido na capital portuguesa (1888-1935), Fernando António Nogueira Pessoa era herdeiro de um crítico musical, falecido em 1893. Pouco tempo depois, sua mãe casou-se com o cônsul de Portugal em Durban, (Natal), logo, Fernando foi levado para a África, onde recebeu uma formação tipicamente britânica, e logo se tornou o aluno mérito da Escola Superior daquela cidade. Pessoa regressou para Lisboa em 1905.

Contido e reservado, cortês e elegante, Pessoa viveu sozinho o resto da sua trajetória. O poeta mudou de residência com frequência, muitas vezes para não ser incomodado pelos amigos e conhecidos, que já sabiam sua direção. Foi uma figura habitual nos cafés literários de Lisboa.

\section{SOBRE OS CRIADORES DA OBRA EM ANÁLISE}

Segundo O Globo (2013), o ilustrador e artista plástico, Eloar Guazzelli, nascido em 1962, é considerado um grande nome no mundo das HQs, e isso se deve a seu relacionamento com a literatura. $O$ artista desenhou e fez adaptações para grandes clássicos literários de autores como: William Faulkner, Eça de Queiroz, J.M.G. Le Clézio e Lygia Fagundes Telles. Contudo, sua conexão com o mundo de Fernando Pessoa é o mais produtivo e peculiar. 


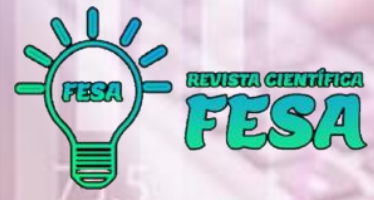

Guazzeli criou também a obra "Eu, Fernando Pessoa", contando com a contribuição da professora, Dr. Suzana Ventura. O desencadear da história gira em torno de uma carta mandada por Fernando Pessoa ao seu colega Adolfo Casais Monteiro, neste escrito, o poeta explica a vida e o nascimento, e descreve fisicamente seus três principais heterônimos: Alberto Caeiro, Álvaro de Campos e Ricardo Reis (descreve ainda seu semi-heterônimo Bernardo Soares).

Já o incomparável, Davi Fazzolari, é o responsável por elaborar o roteiro dos quadrinhos de Fernando Pessoa e Outros Pessoas. Fazzolari leciona língua portuguesa e é mestre em Literatura pela USP- Universidade de São Paulo. Seu apreço pelos quadrinhos nasceu em meados dos anos 1990, quando transferiuse para Portugal e conviveu estreitamente com literatura contemporânea portuguesa.

\section{ANÁLISE DA OBRA: “FERNANDO PESSOA E OUTROS PESSOAS”}

Como ponto de partida, Márcia Veronezi define a função das HQs. Para ela, a HQ é um "meio de comunicação visual bastante rico para ser analisado em sua perspectiva imaginal", entretanto são "consideradas, por alguns estudiosos, como uma forma inferior de comunicação, mas elas são de extrema relevância por atingirem um grande número de leitores, possibilitando a apreciação, até mesmo de quem não sabe ler" (VERONEZI, 2010, p. 12).

Em se tratando de uma transição de uma obra poética clássica para HQs, é importante destacar que este gênero textual foi, e ainda hoje é visto com certo preconceito, por ser considerado uma obra de menor valor. Sobre essa visão, os autores a seguir acrescentam:

Além do inegável preconceito artístico e cultural contra as HQs, que Moacy Cirne afirma perdurar desde a década de 60 até o século XXI, tendo como causa a simples desinformação, Caruso e Silveira (2009) acrescentam que há também certo preconceito científico, perceptível quando alargamos o horizonte dessas potencialidades das HQs.

O legado poético de Fernando Pessoa transpassa a tipologia narrativa do pensamento metafísico e político. A obra apresenta um escritor extremante crítico, dramático, polido, literário, é sobretudo, um poeta de múltiplas características intelectuais, o que dá a obra uma riqueza de detalhes e complexidade na interpretação de sua mensagem. 


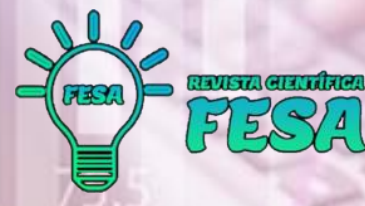

Na produção literária alvo desta pesquisa, os autores retratam os muitos "Fernandos Pessoas" para reconstruí-los como um todo.

Sobre esse o gênero textual, Veronezi (2010, p. 91), afirma que:

\begin{abstract}
A visão é o primeiro sentido a ser utilizado cada vez que o ser humano se depara com alguma coisa nova a visualizar. Para ela, as histórias em quadrinhos comunicam numa linguagem que se vale da experiência visual comum ao criador e ao público. Pode-se esperar dos leitores modernos, uma compreensão fácil da mistura imagem-palavra e da tradicional decodificação do texto. Para ela, a história em quadrinho pode ser chamada 'leitura', num sentido mais amplo que o comumente aplicado ao termo (EISNER, 1995, p. 7 apud VERANEZI, 2010, p.15).
\end{abstract}

Nesse sentido, pode-se notar que a obra Fernando Pessoa e outros Pessoas potencializa a interpretação e criatividade do leitor.

Como ponto de partida desta análise, nota-se que Guazzelli e Fazzolari (2011), permitem que Pessoa se expresse por meio das muitas linguagens visuais e através de seus heterônimos, embalado pela brisa e traços da sua terra natal.

Guazzelli e Fazzolari (2011) apresentam o percurso intelectual do poeta como o relato de uma grande viagem de descoberta em que sempre procurou algo divino e desconhecido. Nela, Pessoa agarra-se a distintos artifícios metafísicos, para conseguiu chegar a uma conclusão definitiva de sua singela significância no mundo. Dessa forma, os autores articulam as imagens à fala de Fernando e nos mergulha no seio do poeta, que conclui que todos os caminhos são verdadeiros, sendo que o que realmente é preciso é navegar pelo mundo das ideias.

Em quase toda sua extensão a obra tem luz própria, os versos originais são fielmente transcritos e reforçados pela linguagem dos traços e pinturas, que contribuem para melhor decodificação da mensagem.

As saudosas avenidas, paisagens, ruas e becos de Lisboa transportam o leitor a um passeio de descoberta, embalados "pela música" dos versos do mestre da poesia portuguesa, Álvaro de Campos, Alberto Caeiro e Bernardo Soares.

Os autores surpreendem o leitor incansavelmente, desde a capa, na qual percebe-se o impacto ao ver a obras de Fernando Pessoa adaptada em HQ, e 
isso ocorre pelo fato de os artistas romperem com a tradição que associa $\mathrm{HQ}$ aos romances, aventura, terror ou peças de teatro.

Ao adaptar para $\mathrm{HQ}$ e recontar as criações do poeta Fernando Pessoa, Guazzelli e Fazzolari (2011) dão liberdade para que "Os Pessoas" transcorram a seus passos lentos e melancólico. A dupla cativa o leitor e o impressiona pela riqueza atribuída à obra, por meio da associação entre palavra e imagem, construindo uma harmonia lírica e visual entre o poeta e seus anseios.

$\mathrm{Na}$ organização da obra e adaptação desta para os quadrinhos, Eloar apresenta sete poemas: quatro pequenos poemas introdutórios "Interlúdios lisboetas", de Pessoa, e um poema longo de cada heterônimo, sendo: "A Tabacaria fora de mim", de Álvaro de Campos, "O Desassossego", de Bernardo Soares, e por fim, "O Pastor de Almas", de Alberto Caeiro. O primeiro poema, "Tabacaria", é o mais extenso e bem-desenvolvido. O segundo é o "Desassossego de Bernardo", cuja narrativa é mais impactante, com personagens bem definidas e falas organizadas em balões pretos e brancos. Já o "Pastor de Almas" é o mais ousado e singelo ao mesmo tempo, onde o tempo é cronológico, as cores são vivas e a arquitetura da cidade se mescla a monotonia do campo e as conclusões do poeta.

\section{PRIMEIROS POEMAS “INTERLÚDIOS LISBOETAS”}

Guazzelli (2011) utiliza de traço e pinceladas depuradas, aliadas os tons de cores luminosas e claras, para recriar e reproduzir um cenário urbano e saudoso da atmosfera lisboeta. Neste momento, os autores deixam a imaginação de Pessoa se mesclar à definição de Lisboa que o toma por inteiro, conforme demonstra no poema Lisboa com suas casas: "Fica só, sem mim, que esqueci porque durmo, Lisboa com suas casas de várias cores." (GUAZZELLI; FAZZOLARI, 2011).

\section{“A TABACARIA FORA DE MIM”, DE ÁLVARO DE CAMPOS}

A obra em análise retrata o terceiro momento poético de Álvaro de Campos, a fase "intimista", na qual o personagem se fecha em seu mundo de pessimismo e desassossegos, para refletir sobre sua insignificância no mundo. A Tabacaria é 
o marco das recordações, grandiosa, sublime e definida, diferente das pessoas que a cerca.

O texto é um poema moderno, caracterizado assim pelos versos livres onde, nas primeiras linhas, o poeta retrata que não é nada, apenas um sonho em questão. "Não sou nada/ Nunca serei nada./ Não posso querer ser nada", ".tenho em mim todos os sonhos do mundo." (GUAZZELLI; FAZZOLARI, 2011).

Da janela de seu quarto, na página catorze, surge um "grito" e o sentimento de revolta, o inconformismo, a desumanização, também, um deprimente vazio e a desilusão. Pessoa sente o desconforto da consciência de ser no mundo, vê a tabacaria como coisa real por fora e a sensação de que tudo é sonho, como coisa real por dentro.

As cores cintilam uma cidade cercada por zumbis, por pessoas sem feição, sem vida, sem distinção e voz. As chaminés falam por todas as vozes que se calam nas páginas 16 e 17.

Nas páginas 18 e 19, Pessoa admira a vitalidade de uma garotinha comendo seu chocolate, cena que the é dolorosa, haja visto que ele não pode viver a mesma verdade com a qual ela come. "Pudesse eu comer chocolate com a mesma verdade com que comes, come, pequena, suja, come!" (GUAZZELLI; FAZZOLARI, 2011).

As imagens nesta passagem reforçam a sensação de não vida, as folhas secas voando, a garota é o único ser alocado em um espaço de luz. Como se a criança fosse o único ser ali, que ainda tivesse um caminho a ser percorrido.

Nos versos seguintes, Guazzelli e Fazzolari (2011) introduzem o pensamento desiludido do poeta em cenas cinzas, cheias de questionamentos, triste, sem vida. Neste momento, a imagem de uma banheira configura a sensação de vazio sentida por Pessoa, em um recipiente onde a água é vetada por correntes. p. 20 e 21. "Vivi, estudei, amei, e até cri,/ E hoje não há mendigo que eu não inveje só por não ser eu." (GUAZZELLI; FAZZOLARI, 2011). Nas páginas 22 e 23, o entrosamento entre o questionamento de Pessoa e as imagens pastéis reforça a significância da tabacaria sobre ele, o dono do estabelecimento, a língua e o mundo.

Conseguintemente, nas páginas 24 e 25, os tons azuis e amarelos reforçam o cenário noturno, onde a tabacaria, o sistema solar e a Via Láctea, passam a ser a únicas verdades que permanecerão eternas. Logo nas páginas seguintes, 
28 e 29, a cidade solitária e Tejo, ancestral - mudo, traduzem a insignificância e sentimento de nada ser do eu lírico. "Ó macio Tejo ancestral e mudo....Nada me dais, nada me tirais, nada sois que eu me sinta." (GUAZZELLI; FAZZOLARI, 2011).

\section{“O DESASSOSSEGO DE BERNARDO”, DE BERNARDO SOARES}

O Livro do Desassossego é uma obra de Bernardo Soares, um dos heterônimos, do poeta Fernando Pessoa, no qual, este, retrata e expõe as perspectivas que podem ser caracterizadas por seu sentido de destacamento, de distância, em relação ao mundo quotidiano. Além disso, há uma consciência aguda de que este mundo é feito de causas necessárias a se encadearem, incluindo aí a consciência das pessoas que o povoam.

Nesta passagem, os tons pretos e brancos, agregam à história o cenário cosmopolita, onde Pessoa tem um diálogo com seu personagem, Bernardo Soares. Neste poema as falas estão organizadas nos balões e a história não segue um percurso linear.

A obra tem partida com o olhar observador e solitário, Bernardo Soares, para a multidão que frequentam alguns restaurantes baratos, em especial para "um homem que aparentava trinta anos, magro, mais alto que baixo", "...com um certo ar de inteligência" nas páginas 33 a 34 (GUAZZELLI; FAZZOLARI, 2011). Trata-se de uma espécie de diário íntimo de Bernardo Soares, em que se refletem histórias de vida, paisagens citadinas e da condição deste em relação ao mundo e ao tempo. "Não sei o que é o tempo. Não sei qual a verdadeira medida que ele tem, se tem alguma. A do relógio sei que é falsa" (GUAZZELLI; FAZZOLARI, 2011).

O discurso se dá em primeira pessoa, em prosa melódica, as imagens configuram o encontro dos personagens e o próprio "livro do desassossego" surge na história como um reforço metalinguístico do que está sendo discutido. Em seguida, tomando o livro pelas mãos, Pessoa passa a analisar os outros integrantes do local na página 37. 
Consequentemente o personagem recorda e descreve sua trajetória ilusória, dos funcionários, do patrão, Vasques e do escritório, cuja rua tem um nome irônico de "Douradores" nas páginas 40 e 41.

Nas páginas seguintes, 42 e 43, Pessoa descreve com tristeza a condição submissa do homem frente ao labor e a sociedade, expondo uma imagem que não condiz com eles e suas realidades.

Campos, não apenas representa uma Lisboa real, mas abarca e compreende principalmente a cidade imaginada, a cidade da intimidade, a cidade da memória, mesmo aquela cidade real que surge no espaço do imaginário. Para ilustrar esse mundo, os artistas, foram procurá-la nas ruas, na geografia urbana, no traçado cotidiano, do lado de fora da janela e nas ruas de Lisboa.

Bernardo está sempre solitário e na condição de mediador entre o tempo, memórias, saudades e desesperança nas páginas 48 e 49.

Não há diferença entre mim e as ruas para o lado da Alfândega, salvo elas serem ruas e eu ser alma, o que pode ser que nada valha, ante o que é a essência das coisas. Há um destino igual, porque é abstrato, para os homens e para as coisas, uma designação igualmente indiferente na álgebra do mistério (GUAZZELLI; FAZZOLARI, 2011).

Nas últimas páginas da obra, Guazzelli e Fazzolari (2011), instalam Pessoa em uma cena na praia, onde o infinito do mar, o trajeto do barco e o desejo do personagem é navegar rumo a um destino sem fim, além do saudoso atracadouro do Tejo. Logo, as imagens de Bernardo na janela, do trem, da mesa do bar, da máquina de escrever e do mundo como um todo, ficam flutuando a mercê do que realmente tem sentido e que permanecerá.

Um barco parece ser um objeto cujo fim é navegar; mas o seu fim não é navegar, senão chegar a um porto. Nós encontramos navegando, sem a ideia do porto a que nos deveríamos acolher. Reproduzimos assim, na espécie dolorosa, a fórmula aventureira dos argonautas: navegar é preciso, viver não é preciso (GUAZZELLI; FAZZOLARI, 2011). 


\section{“O PASTOR DE ALMAS”, DE ALBERTO CAEIRO}

No poema "O pastor de almas", tem-se imagens límpidas e claras. De início, os criadores da obra nos apresentam a figura de um menino conduzindo uma igreja como se esta fosse um brinquedo, uma pipa. Logo, na página 57 , há um poema de García Lorca, escrito no corpo do prédio, recordando um túmulo com uma dedicatória cristã, cravada. A evocação da fé e da natureza, estão presentes em quase todos os cenários dos caminhos. Sempre dando ênfase às expressões: Cristo, amor e ausência.

Nesta prosa, há vida e esperança em um homem simples e cheio de fé, que vaga entre a cidade moderna e o campo ao mesmo tempo, refletindo sobre seu amor e esperança de encontrá-lo. O personagem está situado em um mundo de luz, beleza e harmonia com os animais e natureza, observados pelo próprio Fernando Pessoa em sua janela nas páginas 56 a 62.

Os ilustradores em um tom de "ironia" e associação à nossa realidade expressa na fala de Caeiro reivindicando companhia, em meio a vários prédios habitáveis na página 63.

Nas páginas seguintes, ocorre uma transição espacial, onde o cenário muda e o pastor regressa ao campo junto ao rebanho de ovelhas, logo cai à noite e ele continua a refletir sobre seus sentimentos. "Amar é pensar...não peço nada a ninguém, nem a ela, se não pensar." (GUAZZELLI; FAZZOLARI, 2011).

Em um cenário de arranjo mais frio, o jogo de cores dá à narrativa esse tom e situa Alberto em seu mundo solitário e de abstração.

Já nas páginas que transcorrem para o fim da narrativa, os ilustradores traçam paisagens de desconstrução, na quais os barcos voam pela cidade e esta, por sua vez, parece dormir um profundo sono, sob o olhar do pastor das almas.

Alberto Caeiro então cai em si, e percebe a dura realidade do mundo, um lugar onde tudo é falso e incongruente. Neste momento, as ilustrações do vento agitando e levando tudo pelo ar, alocando o poeta na realidade árdua, então ele próprio se vê navegando nesta nau das ilusões nas páginas 68 a 73 .

Como interpretação conclusiva, Caeiro dedicou-se a simplicidade da vida, e seus pensamentos são extraídos do contato com a natureza e a fé. Ele procurava ver o real e a simplicidade com que a realidade se configura. Para ele, 
as coisas "eram como eram", não havia necessidade de pensar. Tudo era objetivo.

A obra é finalizada com um breve relato e ilustrações sobre Fernando Pessoa e seus Pessoas.

\section{CONSIDERAÇÕES FINAIS}

Os autores, Eloar Guazzelli e Davi Fazzolari, concentraram seus esforços para concretizar uma obra de arte, cujo objetivo é embarcar os diferentes públicos de leitores a desbravar o mundo de Fernando Pessoa e seus heterônimos, em um ritmo menos objetivo que o da poesia e sua linguagem simbolista, os autores representam Pessoa e sua obra na versão em quadrinhos, onde a leitura visual e escrita colaboram para o fácil entendimento das mensagens muitas vezes subjetivas de Fernando Pessoa.

\section{REFERÊNCIAS BIBLIOGRÁFICAS}

CRESPO, Á. Estudos sobre Fernando Pessoa. Editorial Teorema: Lisboa, 1988. Disponível em: http://www.cfh.ufsc.br/ magno/estudsobrfp.htm. Acesso em 20 abr. 2014.

GUAZZELLI, E. Hq Fernando Pessoa e Outros Pessoas. Saraiva: São Paulo, 2011. Disponível em: http://oglobo.globo.com/ blogs/prosa /posts/2013/03/09/ hq-de-guazzelli-sobre-universo-de-fernando-pessoa-489062.asp. Acesso em 20 abr. 2014.

O GLOBO. HQ de Guazzelli sobre o universo de Fernando Pessoa. Rio de Janeiro, 2013

Disponível em: http://oglobo.globo.com/blogs/prosa/posts/2013/03/09/hq-deguazzelli-sobre-universo-de-fernando-pessoa-489062.asp Acesso em 20 abr. 2014.

VERONEZI, M. Quadrinhos na internet: abordagens e perspectivas. Porto Alegre: Asterisco, 2010. 